\title{
Familial risk of dyslexia in Polish first grade pupils based on the ARHQ-PL Questionnaire
}

\begin{abstract}
BACKGROUND
From the perspective of dyslexia, familial risk is the issue most researched worldwide. The familial risk has never been studied in Poland. Results of many studies conducted in Europe, the U.S. and Australia show that children who have a close family member with dyslexia are at greater risk of this disorder than children in the control groups. This conclusion is backed up by the results of research on the genetic aetiology of learning disorders. In the presented study on Polish $1^{\text {st }}$ grade students, the Adult Reading History Questionnaire by Lefly and Pennington (2000) in the Polish adaptation (ARHQ-PL) was used. The connections between the familial risk and the level of reading, spelling, phonological abilities and other cognitive functions were analysed.
\end{abstract}

\section{PARTICIPANTS AND PROCEDURE}

The study covered 513 children, including their parents, from randomly selected primary schools in the Mazowieckie province. According to the ARHQ-PL assumptions, the children's parents were divided into groups taking into account the familial risk level. Children were individually assessed for reading, spelling, phonological abilities, naming speed, phonological memory, vocabulary level and selective attention.
Inter-group comparisons were performed based on the analysed variables for the groups of children whose parents had critical results in the ARHQ. The comparisons identified high risk (or lack of risk), as per sex, age, education level and SES (socio-economical status).

\section{RESULTS}

The results show that there is a significant connection between risk group membership and the level of reading and of the majority of assessed phonological abilities. More significant relationships were determined for the familial risk of dyslexia observed for mothers.

\section{CONCLUSIONS}

The study confirms the diagnostic accuracy of the familial dyslexia risk ratio determined using the ARHQ-PL questionnaire for reading and for the majority of the phonological abilities closely connected with reading. Further longitudinal studies are needed to confirm the prognostic accuracy of diagnosing developmental dyslexia.

\section{KEY WORDS}

familial risk of dyslexia; phonological abilities; parental self-report; dyslexia phenotype; reading and spelling

ORganizations - 1: Specific Learning Disorders Section, Educational Research Institute, Warsaw, Poland .

2: Institute of Psychology, Maria Curie Skłodowska University, Lublin, Poland

AUthors' CONTRIBUtion - A: Study design - B: Data collection - C: Statistical analysis - D: Data interpretation .

E: Manuscript preparation $\cdot F$ : Literature search $\cdot$ G: Funds collection

CORResPonding AUthor - Prof. Grażyna Krasowicz-Kupis, Specific Learning Disorders Section, Educational Research Institute, 8 Górczewska Str., 01-180 Warszawa, Poland, e-mail: g.krasowicz@ibe.edu.pl 


\section{BACKGROUND}

Contemporary studies on dyslexia are clearly focused on the genetic nature of that disorder (Wysocka \& Lipowska, 2010; Wysocka, Lipowska, \& Kilikowska, 2010). Proper documenting of the hereditary factors is a good basis for early indication of increased likelihood of neurodevelopmental disorders in children from families experiencing these type of problems through the generations. Van Bergen et al. introduced
Grażyna Krasowicz-Kupis, Katarzyna M. Bogdanowicz, Katarzyna Wiejak the new term intergenerational transfer of reading and its underlying cognitive skills from parent to child, i.e. an individual configuration of genetic and environmental impacts (van Bergen et al., 2011, 2012).

Studies on the risk of disorders are particularly important for society as they allow for early detection of the disorder in families and for ensuring proper care for affected children.

The term "the risk of disorder" means an increased likelihood of the occurrence of a specific neurodevelopmental disorder in an individual child in the period when such a disorder cannot be fully seen. This may concern different disorder categories, e.g. specific language impairment (SLI) observed in children with late language emergence (LLE), risk of dyscalculia and the risk of dyslexia.

In the important book Preventing Reading Diffculties in Young Children (1998) by Catherine Snow, Susan Burns and Peg Griffin, the sources of reading disorders are analysed and named as follows: child-based sources, including significant cognitive deficits, language development disorders, hearing impairment or attention deficit hyperactivity disorder (ADHD), family-based sources, including family-wide problems with reading and the specific reading environment in the child's family and neighbourhood, community and school based sources quite a large category that includes ineffective methods of teaching at school and poor levels of teaching. Considering the theme of this paper, the second source is particularly important.

As the subject of the studies described here is the risk of dyslexia, we will discuss the dyslexia risk in more detail.

There are two ways of analysing the developmental dyslexia risk. First, it is a familial risk (FR) - researched to a great extent worldwide, but never studied in Poland. Second, it is a behavioural/cognitive risk (BR/CR), being a dyslexia phenotype and studied relatively less frequently (Helland, Plante, \& Hugdahl, 2011). The behavioural dyslexia risk is very well known and effectively diagnosed in Poland by means of the Dyslexia Risk Scale prepared by Marta Bogdanowicz (2002, 2012).

The familial risk of dyslexia focuses on the family experiences as an important factor to increase the likelihood of occurrence of dyslexia in a child from this family. These issues have been widely analysed in longitudinal studies performed worldwide since the 1990s. According to the results of those studies, parents' reading and spelling experiences are strongly correlated with reading achievements of their children at various educational stages (Scarborough, 1989; Lefly \& Pennington, 1996; Elbro, Petersen, \& Borstrom, 1998; Gallagher, Frith, \& Snowling, 2000, and others).

Considering the progress of the research on the genetic basis of developmental dyslexia, it is treated as a multi-factorial phenomena dependent on the polygenic systems quantitative trait loci (QTL) interacting with environmental factors (Elbro et al., 1998). For the purposes of research on dyslexia risk, or the dyslexia itself, this disorder is treated as a continuous variable that is a function of many different factors and configurations of various deficits.

Attempts to quantify the risk of dyslexia have also been made, e.g. using the following measures:

1. Relative risk (RR) ratio shows how much more frequently the familial risk converts into an actual dyslexia as compared to the unexposed population. For example, Gilger, Pennington and DeFries (1991) reported RR = 9.00, Elbro et al. $(1998)-3.10$ and Lefly and Pennington (1996) - 6.50 .

2. Percent ratios of accurate positive prognosis in longitudinal studies. For the families exposed to FR (at least 1 dyslexic parent) the dyslexia prognosis accuracy in children has been 33-66\%; for unexposed families, the percentage of persons with dyslexia is 6-16\% (Pennington \& Lefly, 2001; Boets et al., 2010; van Bergen et al., 2012, and other).

3. Scores of psychometric scales intended for estimation of familial risk, e.g. Adult Reading History Questionnaire (ARHQ), which can also be applied for individual assessment.

The pioneering longitudinal studies of familial risk of dyslexia are those of Scarborough $(1990,1991)$. She conducted longitudinal studies regarding 32 children with FR diagnosis and a control group in the period from 2 to 8 years of life. Then she retrospectively compared 3 separated subgroups: children with FR and dyslexia, children with FR but without dyslexia, and the control group (with no risk). Measures were taken when children were 3,5 and 8 years old. The positive prognosis, assessed for children at the age of 8 , was $65 \%$. The retrospective analyses of their behaviour at the early life stage were quite interesting. Namely, at the age of 3 they had poor vocabulary, grammar deficits and more difficulties in speech production. At the age of 5, when they started to attend schools, their knowledge of letters was poorer, and they had lower levels of phonological awareness and poorer active vocabulary. At the age of 8 they had fully symptomatic dyslexia.

Scarborough's studies triggered a series of larger projects under which the accuracy of the dys- 
lexia prognosis on the basis of familial risk FR was confirmed (Lefly \& Pennington, 1996, 2000; Byrne, Fielding-Barnsley, Ashley, \& Larsen, 1997; Elbro et al., 1998; Gallagher et al., 2000; Snowling, Gallagher, \& Frith, 2003; Muter \& Snowling, 2009; van Bergen et al., 2011, 2012; Scarborough, 1989; Lyytinen \& Lyytinen, 2004; Lyytinen, Eklund, \& Lyytinen, 2005; Snowling, Muter, \& Carroll, 2007; Snowling, Duff, Petrou, Schiffeldrin, \& Bailey, 2011). Below only the most relevant are discussed.

In the US study of Pennington and Lefly (1996, 2001), the authors monitored the development of 67 children with high familial risk and a control group with low FR. The longitudinal study covered children from 5 years old to the end of the $2^{\text {nd }}$ grade (diagnosed dyslexia). The accuracy of the predictivity based on FR was $34 \%$ of the diagnosed dyslexia cases, followed by only $6 \%$ in the control group, which results in a quite high relative risk ratio $R R=5.66$. Numerous cognitive deficits at the school entry were observed in children with FR, i.e. as regards the knowledge of letters, phonological abilities (in particular as regards identification of word-initial sound and sentences, "rhyme-oddity") and naming speed. At the $2^{\text {nd }}$ grade they were positively tested for phonological awareness deficit. Interesting results were also obtained for the FR group in children where dyslexia did not develop. Those children also showed lower scores in reading, spelling and phonology as compared to the control group.

In another interesting longitudinal study Muter and Snowling (2009) monitored the development of 50 children with high familial risk: from 3 years 9 months to $12-13$ years old. This study was divided into 4 phases in which wide-scale tests were performed both for the exposed group and the control group. At phase I, at the age of 3 years 9 months, children with FR showed significant language deficits in terms of vocabulary, expression and grammar, and had noticeably poorer results as regards letter recognition. At phase II, at the age of 6, $50 \%$ of children from the FR group showed significant language development retardations as regards semantics, syntactics and phonology. At phase III, at the age of $8,66 \%$ of children with FR had noticeable difficulties in reading and spelling; in this group there were also reported children who did not show any deficit in this regard at phase II. At phase IV, at the age of 12-13, for $42 \%$ of children with FR dyslexia was diagnosed; in addition to the diagnosed dyslexia, $70 \%$ of children with FR showed language deficits, non-verbal deficits, arithmetics-related problems and attention deficits.

Summarizing the results of the above studies, it must be emphasized that a diagnosis of familial risk is an accurate indication of developmental dyslexia. The dyslexia phenotype included, still in the pre-school period, a language disorder extending beyond phonology. All studies confirmed that the chil- dren with FR but without noticeable reading deficits (which is necessary to diagnose dyslexia) showed behavioural traits of dyslexia, such as phonological processing deficits, spelling difficulties or poor verbal STM (short term memory).

Assessing the familial risk of dyslexia consists in collecting the information about the next of kin of the child, usually being its parents. As a full diagnosis is not always possible, a simpler method is used, namely an interview and a self-report, typically of a retrospective nature, consisting in recalling past reading and spelling experiences.

Rationality of the replacement of the full test with a self-report questionnaire has been confirmed in numerous studies. For example, the results of the studies of Decker, Vogler and DeFries (1989) have shown that the parents who declared reading difficulties in the self-report questionnaire had lower reading test results as compared to the respondents who did not report such difficulties. Schulte-Korne, Deimel, and Remschmidt (1997) verified whether the data from psychometric tests for diagnosing dyslexia can be replaced with the information collected using Finucci's self-report questionnaire (1982, in: Lefly \& Pennington, 2000). They observed a high correlation between the results collected using the questionnaire and the tests. Certainly, not each dyslexia symptoms questionnaire for adults is equally accurate and sufficient to diagnose the familial risk. Numerous conditions must be met regarding the psychometric value, in particular as regards the content accuracy and the adequacy of questions referring to the dyslexia symptoms and the experiences from the school years and the current reading customs and attitudes. The above conditions are met by the ARHQ of Lefly and Pennington (2000), the Polish version of which was used in the present study. High reliability and satisfactory accuracy of the Polish version of the ARHQ are further evidenced by psychometric analyses, and the characteristics of the Polish adaptation will be described in the methodological part.

The purpose of the studies was to verify whether children with high familial risk of dyslexia differ from low-risk children in terms of reading, spelling and phonological abilities. This will be used to determine whether testing the familial risk is the right way to identify children with various reading, spelling and language difficulties that may evolve into fully symptomatic developmental dyslexia in the future. For the above purpose, a group of parents and children was examined, from which group the familial risk subgroups per mother and father and the control groups were selected. For sub-groups, a comparative analysis was performed regarding results achieved by children from the above groups in terms of reading, spelling and phonology, as per age, sex and education level.
Familial risk of dyslexia in Polish first grade pupils 


\section{PARTICIPANTS AND PROCEDURE}

\section{ARHQ-PL QUESTIONNAIRE}

The original ARHQ questionnaire is a formalised and standardised interview with a child's parent and the questions contained therein concern the risk factors in connection with the originating family, i.e. the parents. The questionnaire is a revised version of Finucci's RHQ questionnaire (Reading History Questionnaire) (1982, in: Lefly \& Pennington, 2000). The original questionnaire was supplemented with additional questions and, for responses, the Likert scale rules were applied. As for each individual question, on the line with responses and numbers a respondent marks the number which describes best his/her attitude and experience. The original version of the ARHQ has 23 questions which are the basis for calculating the quantitative result and 3 questions of an informative nature. The authors propose a quantitative assessment system which measures the proportion of actual points obtained to the maximum number of points, and they suggest that familial risk occurs when the percent ratio is higher than 30 .

There are five categories of questions:

- the respondent's experiences at school (e.g. Did your parents ever consider having you repeat any grades in school due to academic failure (not illness)?),

- symptoms of specific difficulties in reading and spelling in the past (e.g. How much difficulty did you have learning to read in elementary school?),

- current symptoms of specific difficulties in reading and spelling (e.g. How would you compare your current reading speed to that of others of the same age and education?),

- reading customs and the current attitude to reading (e.g. How many books do you read for pleasure each year?),

- reading and spelling difficulties of other members of the respondent's family (his/her brothers and sisters or his/her parents, i.e. grandparents of a child suspected of dyslexia (e.g. To the best of your knowledge, did your parents ever report that either one of them had a problem with reading or spelling?).

The ARHQ's authors, Lefly and Pennington (2000), argue that the ARHQ is a fair and reliable tool. Reliability ratios are high (Cronbach's $\alpha$ : .92; stability: .84). Accuracy was confirmed considering the correlation with reading (moderate and high correlation within the range .57-.70), and discriminant analysis data where, based on the ARHQ results, the dyslexia and the reading ability were projected during the hierarchical regression analysis, to which - in subsequent phases - IQ and SES were added. The studies showed that the ARHQ results and SES and IQ explained $51 \%$ of variance in reading among children, and the ARHQ itself explained 25\% (Lefly \& Pennington, 2000).
Using the questionnaire, one must be aware that the ARHQ, like any other self-report tool, cannot be treated as the main tool for diagnosing the risk of dyslexia; it should be treated as a screening test or as a supplementation to other methods. The authors of the questionnaire admit that, according to the research results, approximately $50 \%$ of all children from families exposed to the familial risk of dyslexia will not suffer dyslexia itself and, contrariwise, the fact that a given parent does not declare having reading difficulties in the past does not automatically mean that his/her child will not suffer developmental dyslexia (Lefly \& Pennington, 2000).

It is worth noting that the ARHQ questionnaire is more than ten years old and its prototype is even older. Some questions are deeply rooted in the past and do not use advanced technologies; the latter were taken into account in the Polish version.

For example, the original question: Do you have difficulties in remembering addresses, telephone numbers and dates? refers to the times when the Internet and cell phones were not generally available. Therefore the question should rather be whether you have difficulties in remembering PINs or logins for registering and using various electronic services.

In the first step of adapting the ARHQ and creating the Polish version, a permit from the questionnaire authors was obtained to carry out the procedure; only then did the following phases take place: two-way translations, modifications of some questions, initial pilot studies, subsequent modifications of some questions. The pilot studies included a cognitive interview regarding the structure and content of the tool. The interview was carried out with psychologists who used the tool for research purposes and with the assessed parents. After completing subsequent modifications in the contents and the structure of questions, a psychometric pilot study was carried out, the result of which was the final form of the tool. The current ARHQ-PL version is highly reliable: internal coherence - Cronbach's $\alpha=.83$; split-half reliability Spearman-Brown coefficient $=.85$ and Guttman coefficient $=.84$.

The modified Polish version had two parts: part A with detailed diagnostic questions and part B with informative questions intended for qualitative analyses. Those are direct questions to the child's parents, e.g. Have you ever been diagnosed with dyslexia and/or dysorthography? or Have your other children, except for those being tested, been diagnosed with dyslexia and/or dysorthography?

Part A contains 19 questions taken directly from ARHQ, 2 modified questions and 2 new questions, e.g. How often do you read the information on the Internet, such as blogs, Wikipedia, information portals?, i.e. 22 diagnostic questions in total, evaluated using the scoring scale from 0 to 4 . For each response category, scores are awarded in the following manner: the 
Table 1

Sample ARHQ-PL questions and answers

Each student has difficulties in learning from time to time. As compared to other children in the class, how much effort did you make to learn and to do homework?

\begin{tabular}{ccccc}
\hline None at all & $\begin{array}{c}\text { Less than the } \\
\text { majority }\end{array}$ & $\begin{array}{c}\text { The same as the } \\
\text { majority }\end{array}$ & $\begin{array}{c}\text { More than the } \\
\text { majority }\end{array}$ & $\begin{array}{c}\text { Much more than } \\
\text { the majority }\end{array}$ \\
\hline 0 & 1 & 2 & 3 & 4 \\
\hline
\end{tabular}

highest score means the highest probability of a parent experiencing dyslexia and/or reading and spelling difficulties. A sample question, including the response categories and scoring, is presented in Table 1.

In the analyses discussed in this paper, results from part A of the ARHQ-PL questionnaire were used considering their quantitative nature.

\section{PARTICIPANTS}

The results of studying the familial risk of dyslexia have been worked out as part of the project "Early diagnosis of specific reading and spelling disorders" carried out by the Specific Learning Disorders Unit at the Educational Research Institute in Warsaw.

During the above part of the study, 19 schools from the Mazowieckie Province were randomly selected, i.e. 3 schools from rural communes, 4 schools from rural-urban communes and 12 schools from urban communes. For each of the schools, one $1^{\text {st }}$ grade class and one $2^{\text {nd }}$ grade class were studied. The study was carried out in the period from November 2013 to February 2014. In total, 600 children were invited to take part in the study; however, as the parents' permits and a preselection procedure (children with disabilities or early development support were excluded) were required, only 513 children finally qualified for the study. All children were individually tested for reading, spelling and phonological abilities. Other factors were assessed as well: naming speed, vocabulary, phonological memory, IQ and selective attention. The children's parents were tested using the ARHQ-PL which produced results for parents of 214 children. The ARHQ-PL was filled in for 313 parents, including 114 fathers and 199 mothers. The structure of parents by sex is presented in Figure 1. More than $56 \%$ are tests of both parents. The least frequent were the results for fathers only.

From among the group of parents, individuals with a high and low ARHQ-PL ratio were selected; as such, we created two groups: the group with familial risk and the control group. Distribution of results in the whole group was used, separately for fathers and mothers, and as a group inclusion criterion the upper (group FR) and the lower (group K) quartile were used. Consequently, 4 groups were created:
- a group of fathers with high familial risk of dyslexia (group FR-O, $n=29$ ),

- a group of fathers with low risk, the fathers control group (group K-O, $n=28$ ),

- a group of mothers with high familial risk of dyslexia (group FR-M, $n=54$ ),

- a group of mothers with low risk, the mothers control group (group K-M, $n=50$ ).

\section{OTHER ASSESSMENT TOOLS}

For testing children, the following 4 test groups were used: reading tests, spelling tests, phonological abilities and selected cognitive abilities tests.

The IBE Reading Test Battery included letter naming and recognition, reading of unrelated words and reading of pseudowords. The IBE Spelling Tests Battery included the analysis of graphotactic awareness (assessment of whether pseudowords are accepted as Polish inscriptions), stacking letters into words and writing words the spelling of which is the same as their pronunciation. The Battery of Phonological Tests IBE included tests to measure the phoneme discrimination and the production and recognition of alliterations and rhymes, as well as numerous operations using syllables and phonemes (segmentation, blending, deletion). Words and pseudowords were used in sentences.

In the study, the cognitive abilities were also assessed: the level of IQ using Cattell's Culture Fair Intelligence Test CFT 1-R (Koć-Januchta, 2013b), the level of selective attention using the Intelligence and Development Scales (IDS) Test, sub-test: Selective At-

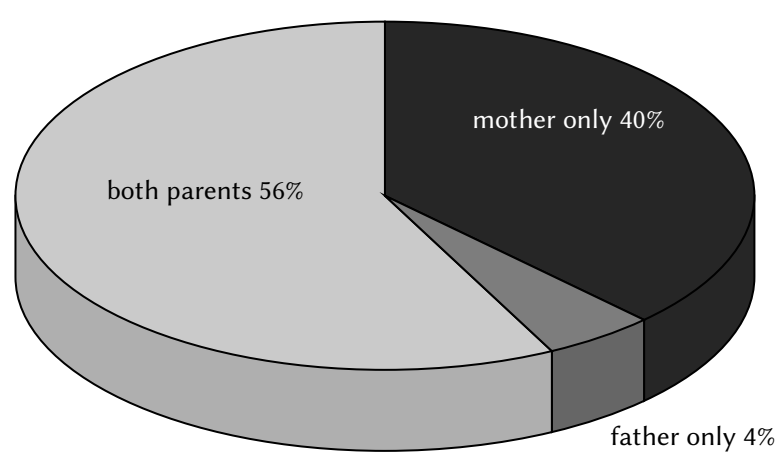

Figure 1. Distribution of parents by sex and the ARHQ-PL assessment.
Familial risk of dyslexia in Polish first grade pupils 
tention (Jaworowska, Matczak, \& Fecenec, 2013), the Vocabulary Test for Children (TSD) (Koć-Januchta, 2013a), the TSN - Rapid Naming Test and the phonological memory test called Zetotest (Bogdanowicz et al., 2009). All the above tests are psychological tests issued by Psychological Test Laboratory of the Polish Psychological Association.

\section{RESULTS}

Grażyna

Krasowicz-Kupis, Katarzyna M.

Bogdanowicz, Katarzyna Wiejak

To assess the relationship between the dyslexia risk group and the reading and spelling level and the phonological and selected cognitive abilities, variance analysis was used. Non-parametric analyses were applied to variables where using variance analysis was not possible.

\section{FAMILIAL RISK AMONG FATHERS (FR-O)}

Table 2 contains ratios and results of the single variable variance analysis (UNIANOVA) which show

Table 2

Reading abilities - the effect size of paternal dyslexia risk group membership

\begin{tabular}{lrcc}
\hline \multicolumn{1}{c}{ Tasks } & \multicolumn{1}{c}{$F$} & $p$ & $\eta^{2}$ \\
\hline Letter naming & 10.40 & .003 & .28 \\
Words & 5.91 & .022 & .18 \\
$\begin{array}{l}\text { "Wyspa" ("the Island") - } \\
\text { pseudowords }\end{array}$ & 9.22 & .005 & .26 \\
\hline
\end{tabular}

Note. All tasks are part of the IBE Battery of Reading Tests prepared by Krasowicz-Kupis, Wiejak, and Bogdanowicz. the size of the effect of paternal dyslexia risk group membership on the results achieved in reading tests. In the case of the spelling tests, not a single difference was observed; therefore they are not discussed below.

Table 3 contains ratios and results of the analysis of variance of a single variable (UNIANOVA) which show the size of the effect of paternal dyslexia risk group membership on the results achieved in phonological tests. A strong effect of the paternal dyslexia risk was observed for the majority of phonological function measures applied. The highest variance explained by FR group membership was observed for: ability to create rhymes (38.10\%), removal of syllables in words (38.10\%) and division of words into sounds (38.00\%).

Differentiated results were obtained after the following covariables were introduced to the variance analysis: IQ (the CFT 1-R test score), child's sex and child's age. As for level I of the reading of phonological abilities, no significant effect of paternal dyslexia risk group membership was observed for the child's sex and age.

After introducing the IQ variable (the score of CFT $1-\mathrm{R}$ - the fluid intelligence) - for the group FR-O in the whole group of children, it became significant in the following phonological tests:

- alliterations - fluency $\left(F=5.17, p=.050, \eta^{2}=.17\right)$; the main effect for the FR group was reduced (by approximately $8 \%$ of the variance being analysed); - syllables - deletion, words $\left(F=6.30, p=.019, \eta^{2}=.20\right)$; the main effect for the FR group was reduced (by approximately $20 \%$ ).

To sum up, supplementing the analysis with the intellectual development factor resulted in reduced variance of phonological variables regarding fluency

Table 3

Phonological abilities - the effect size of paternal dyslexia risk group membership

\begin{tabular}{lccc}
\hline \multicolumn{1}{c}{ Tasks } & $F$ & $p$ & $\eta^{2}$ \\
\hline Alliteration - production & 10.25 & .003 & .28 \\
Alliteration - fluency & 8.70 & .006 & .24 \\
Rhyme - production & 16.60 & $<.001$ & .38 \\
Rhyme - fluency & 5.29 & .029 & .16 \\
Syllables - blending, pseudowords & 8.64 & .007 & .24 \\
Syllables - deletion, words & 16.64 & $<.001$ & .38 \\
Syllables - deletion, words and pseudowords & 8.40 & .007 & .24 \\
Phonemes - blending, words & 10.40 & .003 & .28 \\
Phonemes - blending, pseudowords & 12.19 & .002 & .31 \\
Phonemes - segmentation, words & 16.52 & $<.001$ & .38 \\
Phonemes - segmentation, pseudowords & 10.66 & .003 & .28 \\
\hline
\end{tabular}

Note. All tasks are part of the IBE Battery of Phonological Tests prepared by Krasowicz-Kupis, Wiejak, and Bogdanowicz. 
in alliteration production and, to some larger extent, regarding tasks consisting in deletion of syllables from words; however, the above variables were still strongly dependent on the FR group effect.

The above analyses did not use the SES variable, as the size of the education and the residence place categories as per each group was too small. It must be noted however that parents with a low education level prevailed in the high FR group.

For fathers, the risk group effect was also analysed for the results of other cognitive tests. It proved not significant for the phonological memory test and for the naming speed test. The same non-significant risk group effect was observed for the selective attention test (IDS sub-test) and for the passive and active vocabulary (TSD).

The above results confirmed moderate, but promising, accuracy of diagnosing the child dyslexia risk using the ARHQ-PL questionnaire in fathers' assessment.

\section{FAMILIAL RISK AMONG MOTHERS}

Table 4 contains ratios and results of the single variable variance analysis (UNIANOVA), which show the effect size of maternal dyslexia risk group membership on the results achieved in reading tests. In the case of the spelling tests, only one difference (significant, but moderate) was observed - for the test: Words - stacking letters into words $(F=4.43$, $\left.p=.040, \eta^{2}=.08\right)$.

According to the analyses, there is a significant maternal dyslexia risk group effect in the majority of phonological tests, as shown in Table 5.
Table 4

Reading abilities - the effect size of maternal dyslexia risk group membership

\begin{tabular}{lccc}
\hline \multicolumn{1}{c}{ Tasks } & $F$ & $p$ & $\eta^{2}$ \\
\hline Letter naming & 8.70 & .005 & .15 \\
Words & 4.66 & .036 & .09 \\
$\begin{array}{l}\text { Wyspa ("the Island") - } \\
\text { pseudowords }\end{array}$ & 7.77 & .007 & .13 \\
\hline
\end{tabular}

Note. All tasks are part of the IBE Battery of Reading Tests prepared by Krasowicz-Kupis, Wiejak, and Bogdanowicz.

In case of the maternal dyslexia risk, no effect of sex and age was observed for any of the phonological measures applied.

On the other hand, a significant effect was obtained for IQ (fluid intelligence) - in general, it can be characterised as a reduction in the variance level in the FR group by approximately $2 \%$.

To sum up the familial risk results for mothers, there is a significant dyslexia risk group effect on the reading ability, spelling ability and for the majority of the phonological measures, and the number of significant differences is higher as compared to fathers. The effect also exists for the naming speed, which confirms the accuracy of the dyslexia risk diagnosis. A risk group effect was also observed for cognitive variables not specifically connected with dyslexia, such as the child's vocabulary. The effect was not observed for the selective attention ability. The results presented above confirm the high accuracy of diagnosing the child dyslexia risk using the ARHQ-PL questionnaire for mothers.

Table 5

Phonological abilities - the effect size of maternal dyslexia risk group membership

\begin{tabular}{lccc}
\hline \multicolumn{1}{c}{ Tasks } & $F$ & $p$ & $\eta^{2}$ \\
\hline Phoneme discrimination & 5.03 & .029 & .09 \\
Alliteration - pseudowords & 6.04 & .017 & .11 \\
Alliteration - production & 17.19 & $<.001$ & .26 \\
Alliteration - fluency & 8.17 & .006 & .15 \\
Rhyme - production & 6.00 & .018 & .11 \\
Syllables - blending, pseudowords & 18.72 & $<.001$ & .27 \\
Syllables - deletion, words & 8.51 & .005 & .14 \\
Syllables - deletion, words and pseudowords & 3.97 & .050 & .07 \\
Phonemes - blending, words & 27.43 & $<.001$ & .35 \\
Phonemes - blending, pseudowords & 15.09 & $<.001$ & .23 \\
Phonemes - segmentation, words & 15.04 & $<.001$ & .23 \\
Phonemes - segmentation, pseudowords & 16.23 & $<.001$ & .25 \\
\hline
\end{tabular}

Note. All tasks are parts of the IBE Battery of Phonological Tests prepared by Krasowicz-Kupis, Wiejak, and Bogdanowicz. 


\section{DISCUSSION}

Finally, it is worth mentioning that for some authors the term "the risk of dyslexia" is wider as compared to that used by others listed in this paper - taking into account all three levels included in the Frith (1999) model - biological, cognitive and behavioural. For example, in the questionnaire of Helland et al. (2011) for parents and teachers of five-year olds, questions were added concerning health, lateralization, motor development, linguistic development and heritability. In the studies of McBride-Chang et al. (2011) on early predictors of dyslexia in Chinese children, the following factors were taken into account: the familial history of dyslexia, speech development delay and cognitive abilities. A similar approach was described in a publication of Wong et al. (2012). Beyond any doubt, any increase in the number of dyslexia risk factors used in the studies translates into an improved prognostic quality of the tools being used. Apparently, the optimal solution, both for the diagnostics and for the scientific research, is to determine the risk of dyslexia and of other neurodevelopmental disturbances based on a comprehensive diagnosis that includes familial risk questionnaires as well as behavioural and cognitive risk assessment in children.

It must be emphasized that the increased familial risk of dyslexia is not only the result of genetic background. A factor of equal importance is the cultural transfer. The study results show that reading customs and the education level as well as the social status of a parent are effective predictors of his/her child's reading progress (Elbro et al., 1998; Lefly \& Pennington, 2000).

\section{CONCLUSIONS}

The main conclusions drawn from the studies are those concerning the accuracy of the diagnosis of familial risk of dyslexia based on the ARHQ-PL questionnaire. The analyses discussed in this paper show that studying the familial risk, both for fathers and for mothers, is the right way to identify children with various reading, spelling and linguistic difficulties that may evolve into fully symptomatic developmental dyslexia in the future. Familial risk may be determined a long time before the education process starts and without any involvement on the child's side, which allows for very early intervention.

The studies above are in line with the mainstream international analyses of early predictors of neurodevelopmental and learning disorders. An interesting fact is that the results of using the FR ratio suggest that genetic predispositions may be modified by environmental factors.

The Polish adaptation of the ARHQ-PL questionnaire allows for early diagnosis of the risk of dys- lexia. However, the actual prognostic usefulness of it still needs to be ascertained.

The important future task as regards diagnosing the familial dyslexia risk is normalization of the questionnaire and adjustment of the psychometric criteria for determining the familial risk. The most important aim of the project is the evaluation of the prognostic accuracy in conjunction with the other reading, spelling and cognitive function measures or, in other words, the assessment of the effectiveness of combining FR with BR/CR for predicting reading disorders.

This research is co-financed by the EU from the European Social Fund as part of the project: Quality and effectiveness of education and strengthening of institutional research capabilities.

\section{References}

Boets, B., De Smedt, B., Cleuren, L., Vandewalle, E., Wouters, J., \& Ghesquière, P. (2010). Towards a further characterization of phonological and literacy problems in Dutch-speaking children with dyslexia. British Journal of Developmental Psychology, 28, 5-31.

Bogdanowicz, M., Jaworowska, A., Krasowicz-Kupis, G., Matczak, A., Pelc-Pękala, O., Pietras, I., Stańczak, J., \& Szczerbiński, M. (2009). Dysleksja 3. Diagnoza dysleksji u uczniów klasy III szkoty podstawowej [Dyslexia 3. Diagnosis of dyslexia in $3^{\text {rd }}$ graders. Diagnostic guide]. Warszawa: Pracownia Testów Psychologicznych PTP.

Bogdanowicz, M. (2002). Ryzyko dysleksji. Problem $i$ diagnozowanie [The risk of dyslexia - the problem and assessment]. Gdańsk: Wydawnictwo Harmonia.

Bogdanowicz, M. (2012). Ryzyko dysleksji, dysortografii i dysgrafii [The risk of dyslexia, dysorthography and dysgraphy]. Gdańsk: Wydawnictwo Harmonia.

Bogdanowicz, M., \& Krasowicz-Kupis, G. (2003). Kwestionariusz objawów dysleksji u dorosłych Michaela Vinegrada [Micheal Vinegard's adults dyslexia checklist]. In: W. Turewicz (ed.), Jak pomóc dziecku z dysortografia [How to support the child with dysorthography] (pp. 25-27). Zielona Góra: ODN.

Byrne, B., Fielding-Barnsley, R., Ashley, L., \& Larsen, K. (1997). Assessing the child's and the environment's contribution to reading acquisition: What we know and what we don't know. In: B. A. Blachman (ed.), Foundations of reading acquisition and dyslexia: Implications for early intervention (pp. 265-285). Mahwah, NJ: Lawrence Erlbaum Associates.

Decker, S. N., Vogler, G. P., \& DeFries, J. C. (1989). Validity of self-reported reading disability by 
parents of reading-disabled and control children. Reading and Writing, 1, 327-331.

Elbro, C., Petersen, D. K., \& Borstrom, I. (1998). Predicting dyslexia from kindergarten: The importance of distinctness of phonological representations of lexical items. Reading Research Quarterly, 33, 36-60.

Frith, U. (1999). Paradoxes in the Definition of Dyslexia. Dyslexia, 5, 192-214.

Gallagher, A., Frith, U., \& Snowling, M. J. (2000). Precursors of literacy delay among children at genetic risk of dyslexia. Journal of Child Psychology and Psychiatry and Allied Disciplines, 41, 203-213.

Gilger, J. W., Pennington, B. F., \& DeFries, J. C. (1991). Risk for Reading Disability as a Function of Parental History in Three Family Studies. Reading and Writing, 3, 205-217.

Helland, T., Plante, E., \& Hugdahl, K. (2011). Predicting Dyslexia at Age 11 from a Risk Index Questionnaire at Age 5. Dyslexia, 17, 207-226.

Jaworowska, A., Matczak, A., \& Fecenec, D. (2013). Skale Inteligencji i Rozwoju IDS [IDS Intelligence and Development Scales]. Warszawa: Pracownia Testów Psychologicznych PTP.

Koć-Januchta, M. (2013a). Test Stownikowy dla Dzieci [TSD. Vocabulary Test For Children]. Warszawa: Pracownia Testów Psychologicznych PTP.

Koć-Januchta, M. (2013b). CFT 1-R Neutralny Kulturowo Test Inteligencji Cattella - wersja 1 zrewidowana przez Rudolfa $\mathrm{H}$. Weißa i Jürgena Osterlanda [CFT 1-R Cattell Culture Fair Intelligence Test, revised by Rudolf $\mathrm{H}$. Wei $\beta$ and Jurgen Osterland]. Warszawa: Pracownia Testów Psychologicznych PTP.

Lefly, D. L., \& Pennington, B. F. (1996). Longitudinal study of children at high family risk for dyslexia: The first two years. In: M. L. Rice (ed.), Toward a genetics of language (pp. 49-75). Hillsdale, NJ: Lawrence Erlbaum.

Lefly, D. L., \& Pennington, B. F. (2000). Reliability and validity of the adult reading history questionnaire. Journal of Learning Disabilities, 33, 286-296.

Lyytinen, P., \& Lyytinen, H. (2004). Growth and predictive relations of vocabulary and inflectional morphology in children with and without familial risk for dyslexia. Applied Psycholinguistics, 25, 397-411.

Lyytinen, P., Eklund, K., \& Lyytinen, H. (2005). Language Development and Literacy Skills in Latetalking Toddlers with and without Familial Risk for Dyslexia. Annals of Dyslexia, 55, 166-192.

McBride-Chang, C., Lam, F., Lam, C., Chan, B., Fong, C., Wong, T., \& Wong, S. (2011). Early predictors of dyslexia in Chinese children: familial history of dyslexia, language delay, and cognitive profiles. Journal of Child Psychology and Psychiatry, 52, 204-211.

Murray, T. S., Kirsch, I. S., \& Jenkins, L. B. (1998). Adult literacy in OECD countries: Technical report on the first International Adult Literacy Survey (Technical Report NCES 98-053). Washington DC: US Department of Education, National Center for Education Statistics.

Muter, V., \& Snowling, M. J. (2009). Children at Familial Risk of Dyslexia: Practical Implications from an At-Risk Study. Child and Adolescent Mental Health, 14, 37-41.

Pennington, B. F., \& Lefly D. L. (2001). Early Reading Development in Children at Family Risk for Dyslexia. Child Development, 72, 816-833. DOI: 10.1111/1467-8624.00317

Scarborough, H. S. (1989). Prediction of Reading Disability from Familial and Individual Differences. Journal of Educational Psychology, 81, 101-108.

Scarborough, H. S. (1990). Very early language deficits in dyslexic children. Child Development, 61, 1728-1743.

Scarborough, H. S. (1991). Antecedents to reading disability: Preschool language development and literacy experiences of children from dyslexic families. Reading and Writing, 3, 219-233.

Schulte-Korne, G., Deimel, W., \& Remschmidt, H. (1997). Can self-report data on deficits in reading and spelling predict disability as defined by psychometric tests? Reading and Writing, 9, 55-63.

Smythe, I. (ed.). (2007). Dysleksja. Przewodnik dla dorostych [Dyslexia. The guidebook for adults]. Sofia: Leonardo da Vinci.

Smythe, I., \& Everatt, J. (2001). Adult Checklist. Available at: http://www.bdadyslexia.org.uk/files/ Adult\%20Checklist.pdf (20.04.2011).

Snow, C., Burns, S., \& Griffin, P. (1998). Preventing Reading Difficulties in Young Children. Washington: DC: National Academy Press.

Snowling, M., Dawes, P., Nash, H., \& Hulme, C. (2011). Validity of a Protocol for Adult Self-Report of Dyslexia and Related Difficulties. Published online in Wiley Online Library (wileyonlinelibrary.com). DOI: 10.1002/dys.1432

Snowling, M. J., Duff, F., Petrou, A., Schiffeldrin, J., \& Bailey, A. M. (2011). Identification of children at risk of dyslexia: the validity of teacher judgments using 'Phonic Phases'. Journal of Research in Reading, 34, 157-170.

Snowling, M. J., Gallagher, A., \& Frith, U. (2003). Family risk of dyslexia is continuous: individual differences in the precursors of reading skill. Child Development, 74, 358-373.

Snowling, M. J., Muter, V., \& Carroll, J. (2007). Children at family risk of dyslexia: a follow-up in early adolescence. Journal of Child Psychology and Psychiatry, 48, 609-618.

Torppa, M., Eklund, K., van Bergen, E., \& Lyytinen, H. (2011). Parental Literacy Predicts Children's Literacy: A Longitudinal Family-Risk Study. Dyslexia, 17, 339-355.

Van Bergen, E., de Jong, P. F., Plakas, A., Maassen, B., $\&$ van der Leij, A. (2012). Child and Parental Liter-
Familial risk of dyslexia in Polish first grade pupils 
acy Levels within Families with a History of Dyslexia. Journal of Child Psychology and Psychiatry, 53, 28-36. DOI: 10.1111/j.1469-7610.2011.02418.x

Van Bergen, E., De Jong, P. F., Regtvoort, A., Oort, F., Van Otterloo, S., \& Van der Leij, A. (2011). Dyslexia, 17, 2-18. DOI: 10.1002/dys.423

Wong, S., McBride-Chang, C., Lam, C., Chan, B., Lam, F. W. F., \& Doo, S. (2012). The Joint Effects of Risk Status, Gender, Early Literacy and Cognitive Skills on the Presence of Dyslexia Among a Group

Grażyna Krasowicz-Kupis, Katarzyna $M$. Bogdanowicz, Katarzyna Wiejak of High-Risk Chinese Children. Published online in Wiley Online Library (wileyonlinelibrary.com), 40-57. DOI: 10.1002/dys. 1434

Wysocka, A., \& Lipowska, M. (2010). Genetyczne podłoże współwystępowania ADHD i dysleksji rozwojowej [Genetic background of comorbidity between ADHD and developmental dyslexia]. Psychiatria i Psychologia Kliniczna, 10, 189-194.

Wysocka, A., Lipowska, M., \& Kilikowska, A. (2010). Genetics in solving dyslexia puzzles: the overview. Acta Neuropsychologica, 8, 315-331. 